\title{
Expression of pancreatic regenerating gene in lung and intestinal tissue correlates with the severity of disease in rats with acute necrotizing pancreatitis
}

\author{
HAO-LIN HU, QI ZHANG, BO KONG and XIN SHI \\ Department of General Surgery, Zhongda Hospital, Southeast University, Nanjing, Jiangsu 210009, P.R. China
}

Received July 1, 2012; Accepted October 31, 2012

DOI: $10.3892 / \mathrm{mmr} .2012 .1187$

\begin{abstract}
The aim of this study was to investigate the expression pattern of regenerating gene I (Reg I) in the lung and intestinal tissues of rats with acute necrotizing pancreatitis (ANP), as well as the correlation of Reg I expression with lung and intestinal injury. Sprague-Dawley rats were randomly allocated to control $(n=40)$ and ANP $(n=80)$ groups. The rats in the control group received laparotomy only. In the ANP group, 3\% sodium taurocholate was injected into the pancreatic duct to develop the ANP model. Reverse transcription-polymerase chain reaction (RT-PCR) was performed to detect the Reg I mRNA levels in the pancreas, intestine and lung. The pathological changes in the pancreas, intestine and lung were observed and the serum amylase levels, the wet/dry weight ratio of the lung and the permeability of the intestinal mucosa were measured. The measured parameters were found to correlate with the Reg I mRNA levels. Reg I mRNA was more highly expressed in the pancreas, intestine and lung in the ANP rats than in the control group. The Reg I expression levels were positively correlated with the pathological scores, serum amylase levels, lung pathological scores, lung tissue wet/dry ratios, intestinal pathological scores and intestinal permeability. The levels of Reg I were increased in the lung and intestinal tissue of the ANP rats and the expression levels of Reg I correlated closely with the severity of the lung and intestinal injury.
\end{abstract}

\section{Introduction}

Acute necrotizing pancreatitis (ANP) is a disease with severe complications and high mortality, despite treatment (1). Patients with ANP may suffer from pancreatitis-associated respiratory dysfunction and gastrointestinal mucosal lesions. Respiratory dysfunction, presenting as acute lung injury (ALI)

Correspondence to: Dr Xin Shi, Department of General Surgery, Zhongda Hospital, Southeast University, 87 Dingjiaqiao, Nanjing, Jiangsu 210009, P.R. China

E-mail: xinshicn@163.com

Key words: pancreatic regenerating gene, acute necrotizing pancreatitis, pancreatitis-associated lung injury, intestinal mucosal lesion, intestinal permeability or acute respiratory distress syndrome (ARDS), is frequent in acute pancreatitis and is a major component of multiple organ dysfunction syndrome (MODS). Approximately one-third of all mortalities from acute pancreatitis are reported to occur prior to admission to hospital and, in the majority of cases, are associated with ALI (2). As a consequence of severe acute pancreatitis at the early stage, intestinal barrier failure also contributes to the progression of pancreatitis. It has been reported that an early increase in intestinal permeability occurs in patients with severe acute pancreatitis and correlates with the occurrence of endotoxemia, MODS and mortality (3).

The regenerating gene ( $\mathrm{Reg}$ ) is a multi-gene family in humans that is involved in tissue regeneration. Okamoto classified the members of the Reg family and Reg-related genes from human, rat and mouse into three subclasses, types I, II and III (4). Regenerating gene I (Reg I) is mainly expressed in the pancreas and the gastrointestinal tract and is involved in the pathophysiology of gastritis, pancreatitis, cancer, inflammatory bowel disease and type 1 diabetes (5-7). Previous studies have revealed that Reg I is important in acute pancreatitis due to its involvement in the regeneration and recovery from the pancreatic injury (8). Viterbo et al revealed a protective role of Reg I in pancreatitis by the administration of anti-Reg I antibody to neutralize the pancreatic Reg protein or siRNA to knockout the Reg gene in animal models $(9,10)$. However, studies concerning the expression of Reg I in pancreatitisinduced lung injury and intestinal injury following ANP are lacking and the correlation between Reg I and the severity of the disease remains unclear.

\section{Materials and methods}

Induction of ANP. A total of 90 male Sprague-Dawley rats, weighing 230-270 g, were randomly divided into 2 groups: an ANP group $(n=60)$ and a control group $(n=30)$. The animals were anesthetized with $10 \mathrm{mg} / \mathrm{ml}$ ketamine at a dose of $10 \mathrm{mg} / 100 \mathrm{~g}$ body weight injected intraperitoneally. ANP was induced by the retrograde injection of 3\% sodium taurocholate into the pancreatic duct. The abdominal cavity was then entered through a midline incision. After identifying the duodenum and pancreas, the common bile duct was ligated at the position of the hepatic hilum. A duodenotomy was performed $\sim 1 \mathrm{~cm}$ distal to the opening of the biliopancreatic duct into the duodenum and a polyethylene catheter was gently 
cannulated into the pancreatic duct via the duodenotomy incision. Sodium taurocholate solution (3\%) was slowly injected at a constant rate of $0.5 \mathrm{ml} / \mathrm{min}$. The catheter was removed after being kept in place for $30 \mathrm{~min}$. The rats in the control group underwent sham surgery (open laparotomy with immediate closure). All animal experiments were evaluated and approved by the Animal and Ethics Review Committee of the Southeast University.

Morphologicalobservation and histopathological assessment. Fresh tissue was collected and fixed in $10 \%$ formaldehyde for $12 \mathrm{~h}$, dehydrated in a conventional manner, embedded in paraffin, cut into slices and stained with hematoxylin and eosin (H\&E). The morphological observation and histological assessment were conducted by an experienced pathologist, who was unaware of the sample identity, using previously described criteria $(11,12)$.

Harvesting of sample. A total of 20 animals were sacrificed at each time point (12, 24 and $36 \mathrm{~h}$ after the induction of ANP). Ten animals per group (sham operated) were used as the controls. Samples of the pancreas, lung and terminal ileum were harvested and a blood sample was collected from the hepatic portal vein of each animal at the time of pancreatectomy.

Lung wet/dry weights measurement. To determine the lung wet/dry weight ratio, the whole left lung, lobes or segments of the peripheral lung were weighed after initial removal and after drying in an oven at a constant temperature of $160^{\circ} \mathrm{C}$ for $48 \mathrm{~h}$.

Intestinal permeability determination. Prior to the closure of the midline incision, $3.7 \mathrm{MBq}$ technetium-99m diethylenetriaminepentacetic acid ( $\left.{ }^{99 \mathrm{~m}} \mathrm{Tc}-\mathrm{DTPA}\right)$ was slowly injected into the apical portion of the jejunum of the rats in the ANP group. Urine was collected 12, 24 and $36 \mathrm{~h}$ after the ingestion of the tracer. The radioactivity of the tracer was detected and the urinary excretion rate of ${ }^{99 \mathrm{~m}} \mathrm{Tc}-\mathrm{DTPA}$ was calculated according to the following equation: urinary excretion rate of ${ }^{99} \mathrm{~m}$ Tc-DTPA $=$ [(urinary count-background $) \mathrm{x}$ urinary volume/ (standard count-background) x 1000] x 100 (13).

Reverse transcription-polymerase chain reaction (RT-PCR). Total RNA was extracted from the frozen tissue using TRIzol (Invitrogen Life Technologies, Carlsbad, CA, USA) according to the manufacturer's instructions and the integrity of the RNA was confirmed by $1 \%$ formaldehyde-agarose gel electrophoresis. The synthesis of cDNA was conducted using an RT-PCR kit (Takara Bio, Inc., Shiga, Japan) following the recommendations of the manufacturer. The primers were designed using Primer premier software. The primer sequences for the Reg I gene were: upstream: 5'-GCCAGGAGGCTGAAGAAG-3' and downstream: 5'-CCAGTGTCCCAGGATTTG-3'. Moreover, the primer sequences for endogenous control GAPDH were: upstream: 5'-GTTCAACGGCACAGTCAA-3' and downstream: 5'-CCTCAGTGTAGCCCAGGAT-3'. All primers were synthesized by Invitrogen Life Technologies. PCR was carried out in a $25-\mu 1$ reaction mixture with $3 \mu \mathrm{l}$ cDNA reaction product as the template mixed with $22 \mu \mathrm{l}$ PCR mixture (including $25 \mathrm{mM} \mathrm{MgCl}{ }_{2}, 5 \mathrm{U} / \mu \mathrm{l} \mathrm{Taq}$ polymerase and $1.5 \mu \mathrm{l}$ of each primer). The thermal cycling process began with an
Table I. Serum amylase activity (U/l).

\begin{tabular}{|c|c|c|c|}
\hline Group & $12 \mathrm{~h}$ & $24 \mathrm{~h}$ & $36 \mathrm{~h}$ \\
\hline Control & $1,004 \pm 94.7$ & $1,405 \pm 84.5$ & $1,134 \pm 146.1$ \\
\hline ANP & $3,793 \pm 185.9^{a}$ & $5,548 \pm 191.5^{\mathrm{a}}$ & $7,071 \pm 135.4^{\mathrm{a}}$ \\
\hline
\end{tabular}

ANP, acute necrotizing pancreatitis. ${ }^{\mathrm{a}} \mathrm{P}<0.01$, compared with the control group.

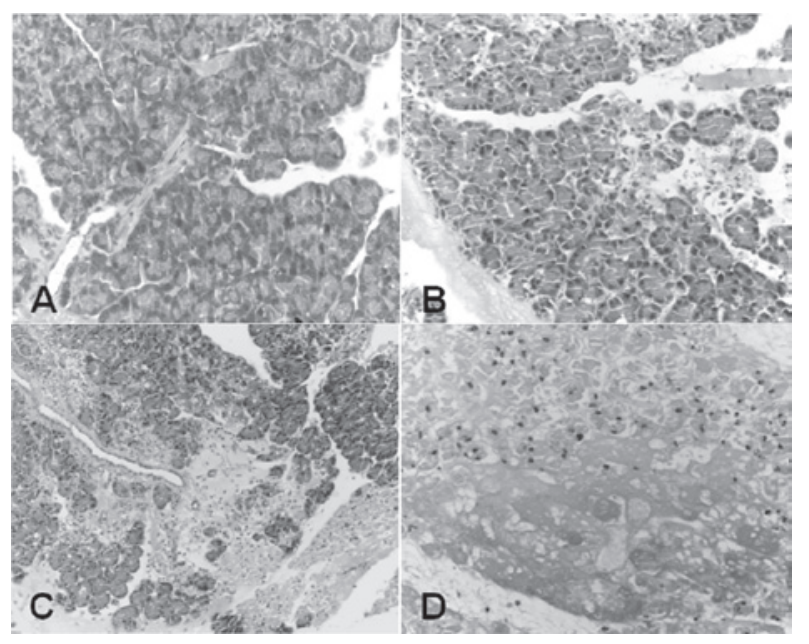

Figure 1. Pathology of the pancreas in the control and ANP groups (hematoxylin and eosin stain, $\mathrm{x} 200$ ). (A) Control. (B-D) Rats with acute necrotizing pancreatitis (ANP), 12, 24 and $36 \mathrm{~h}$ post-surgery, respectively.

initial denaturing step at $94^{\circ} \mathrm{C}$ for 2 min followed by a denaturing step of $30 \mathrm{sec}$, and annealing at $54^{\circ} \mathrm{C}$ for another $30 \mathrm{sec}$. The synthesis of new DNA was initiated with an extension step lasting $1 \mathrm{~min}$ as the reaction temperature was raised to $72^{\circ} \mathrm{C}$. The next cycle began with a return to $95^{\circ} \mathrm{C}$ for denaturation. The process ran for 32 cycles and involved a final step at $72^{\circ} \mathrm{C}$ for $7 \mathrm{~min}$. After amplification, the RT-PCR products were submitted to electrophoresis on $1.5 \%$ agarose gel $(100 \mathrm{~V}$, $40 \mathrm{~min}$ ). All PCR assays were conducted in triplicate and the results were semi-quantitated as the ratio amplicon/GAPDH and presented as the mean $\pm \mathrm{SD}$.

Histological scoring. The histopathological score was evaluated based on the severity of injury in the pancreas, lung and intestine and used grading scale criteria. In the pancreas, according to the degree of edema, acinar necrosis, fat necrosis and perivascular infiltrate, the score varied from 0 to 4 and then the total score was obtained. Six parameters including hyaline membranes, microthrombi, edema, interstitial infiltrates, atelectasis and hemorrhage were taken into account in the microscopic observation of lung tissue. A score of 0 represents normal tissue, 1 shows discrete or small foci, 2 indicates moderate or large foci and 3 indicates severe or diffuse lesions. In the intestine, grade 0 represents normal mucosa and grades 1 to 5 indicate increasing damage of villi. Grades 6 to 8 represent crypt layer infarction to transmural infarction. A low score indicates a mild lesion, and a high score depicts serious damage. The mean was calculated from the sum of the respective scores. 
Table II. Histological scores of the pancreas.

\begin{tabular}{lccc}
\hline Group & $12 \mathrm{~h}$ & $24 \mathrm{~h}$ & $36 \mathrm{~h}$ \\
\hline Control & $0.5 \pm 0.53$ & $0.4 \pm 0.52$ & $0.6 \pm 0.7$ \\
ANP & $8.2 \pm 1.40^{\mathrm{a}}$ & $10.1 \pm 1.80^{\mathrm{a}}$ & $11.3 \pm 1.81^{\mathrm{a}}$
\end{tabular}

ANP, acute necrotizing pancreatitis. ${ }^{a} \mathrm{P}<0.01$, compared with the control group.

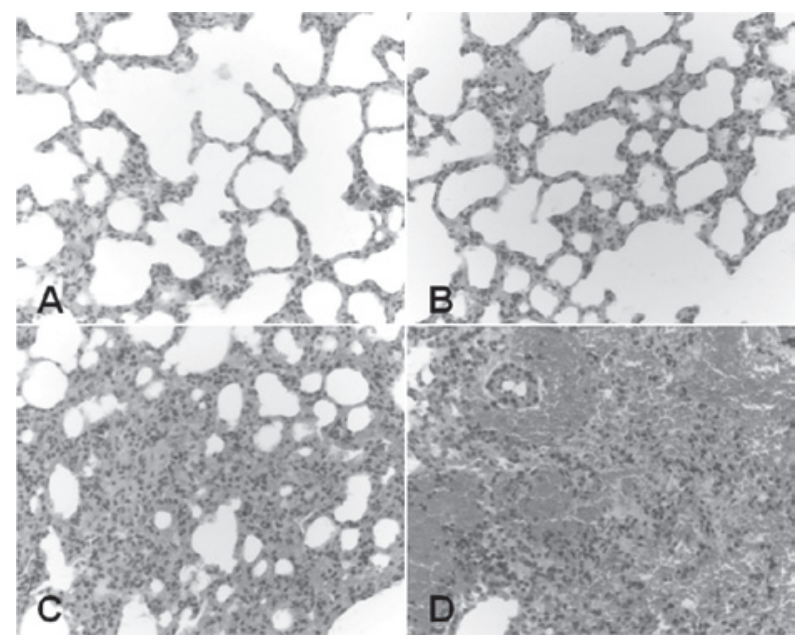

Figure 2. Pathology of the lung in the control and ANP groups (hematoxylin and eosin stain, x200). (A) Control. (B-D) Rats with acute necrotizing pancreatitis (ANP), 12, 24 and 36 post-surgery, respectively.

Statistical analysis. Statistical analysis was achieved using SPSS software and comparisons between groups were made using an unpaired Student's t-test. The correlation between Reg I and each histological score was assessed using the Pearson correlation test. Data are expressed as the mean \pm SD and $\mathrm{P}<0.05$ was considered to indicate a statistically significant result.

\section{Results}

Serum amylase activity and histological evaluation of the pancreas. The presence of ANP in the taurocholate-induced animals was confirmed by serum amylase activity and histology (Table I and Fig. 1). As demonstrated in Table I, the levels of circulating amylase in the ANP group were significantly higher than those in the sham-operated animals 12,24 and $36 \mathrm{~h}$ after surgery $(\mathrm{P}<0.05)$. Bloody ascites in the abdominal cavity, pancreatic bleeding spots and necrosis were observed when harvesting the samples from the ANP animals. The histological worsening of the pancreatitis in the pancreatic parenchyma following sodium taurocholate treatment was evidenced by hemorrhage (Fig. 1B and C) and necrosis (Fig. 1D) as compared with the control (Fig. 1A). The histological scoring of the pancreas was conducted according to the criteria previously described by Schmidt et al (14). As shown in Table II, the histological scores for the pancreas 12, 24 and $36 \mathrm{~h}$ after injection in the ANP group were significantly higher than those in the controls $(8.2 \pm 1.40,10.1 \pm 1.80,11.3 \pm 1.81$ vs. $0.5 \pm 0.53,0.4 \pm 0.52,0.6 \pm 0.7$, respectively, $\mathrm{P}<0.01)$.
Table III. Histological scores of lung injury.

\begin{tabular}{lccr}
\hline Group & $12 \mathrm{~h}$ & $24 \mathrm{~h}$ & \multicolumn{1}{c}{$36 \mathrm{~h}$} \\
\hline Control & $0.5 \pm 0.71$ & $0.3 \pm 0.48$ & $0.3 \pm 0.67$ \\
ANP & $8.95 \pm 1.88^{\mathrm{a}}$ & $12.05 \pm 2.11^{\mathrm{a}}$ & $13.65 \pm 1.81^{\mathrm{a}}$
\end{tabular}

ANP, acute necrotizing pancreatitis. ${ }^{\text {a }} \mathrm{P}<0.01$, compared with the control group.

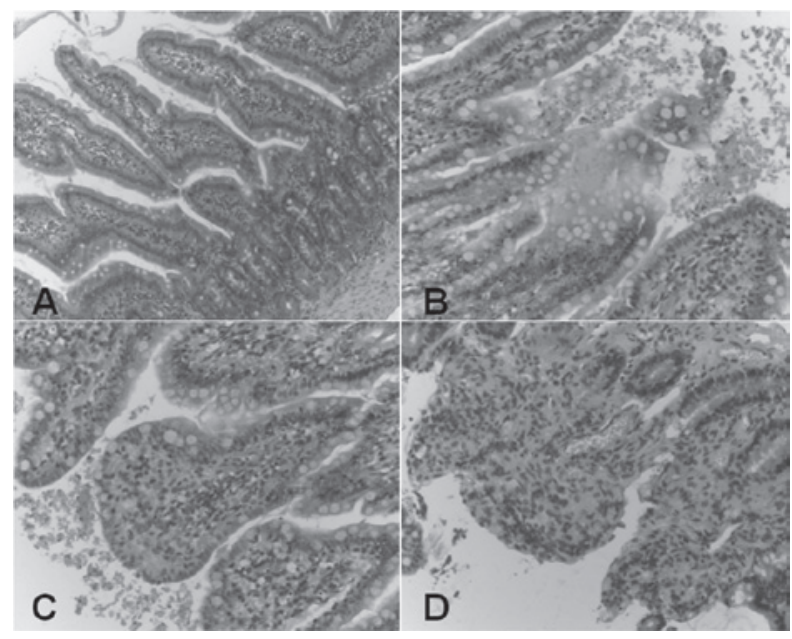

Figure 3. Pathology of the intestine in the control and ANP groups (hematoxylin and eosin stain, $\mathrm{x} 200$ ). (A) Control. (B-D) Rats with acute necrotizing pancreatitis (ANP), 12, 24 and 36 h post-surgery, respectively.

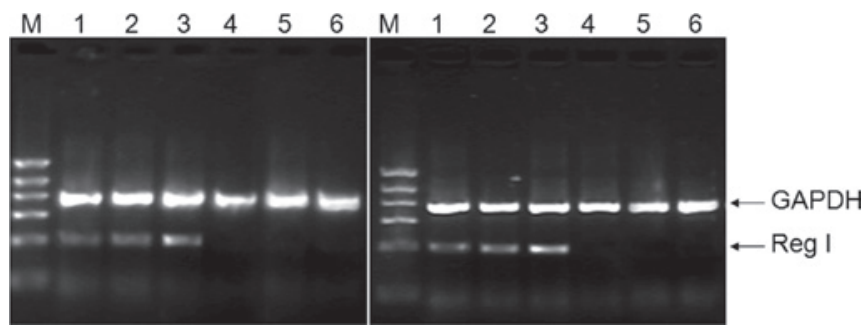

Figure 4. Expression of pancreatic regenerating gene (Reg I) mRNA in rat lung and intestinal tissue. Lanes 1-3, acute necrotizing pancreatitis (ANP) 12,24 and 36 h post-surgery, respectively; lanes 4-6, control, 12, 24 and $36 \mathrm{~h}$ post-surgery, respectively; M, DNA marker (from top to bottom: 1100, 900, $700,500,300$ and $100 \mathrm{bp}$ ).

Histological evaluation of pulmonary injury. As shown in Fig. 2, the pulmonary injury induced by ANP was characterized by thickening of the alveolar wall, pulmonary edema (Fig. 2B), infiltration of neutrophils and hemorrhage (Fig. 2C and D) compared with the controls (Fig. 2A). Disruption of the pulmonary alveolus followed by consolidation and interstitial vasodilation was also observed $36 \mathrm{~h}$ after injection (Fig. 2D). The histological scores for lung injury were calculated according to previously described criteria (11). As demonstrated in Table III, the histological scores for pulmonary injury 12,24 and $36 \mathrm{~h}$ after injection in the ANP group were significantly higher than those in the controls $(8.95 \pm 1.88,12.05 \pm 2.11$, $13.65 \pm 1.81$ vs. $0.5 \pm 0.71,0.3 \pm 0.48,0.3 \pm 0.67$, respectively, $\mathrm{P}<0.01)$. The ratios of rat lung wet/dry weights were calculated 
A

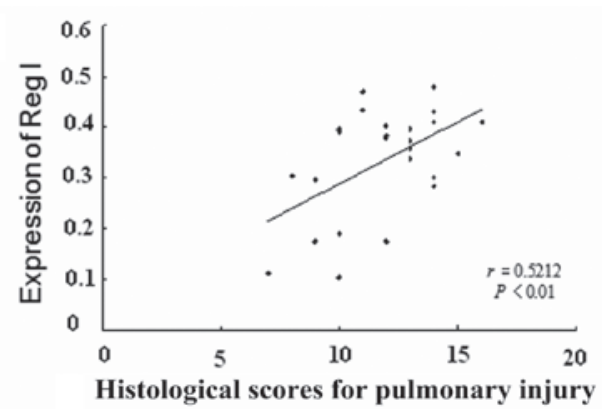

C

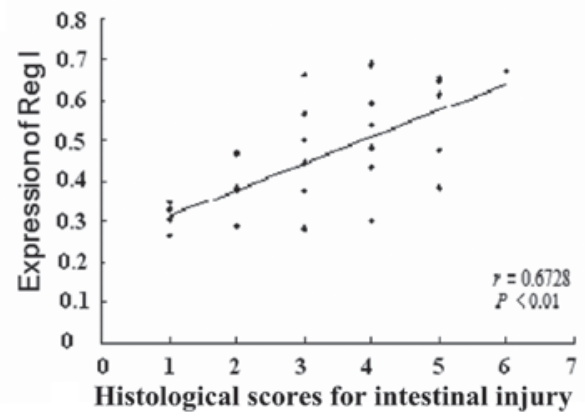

B

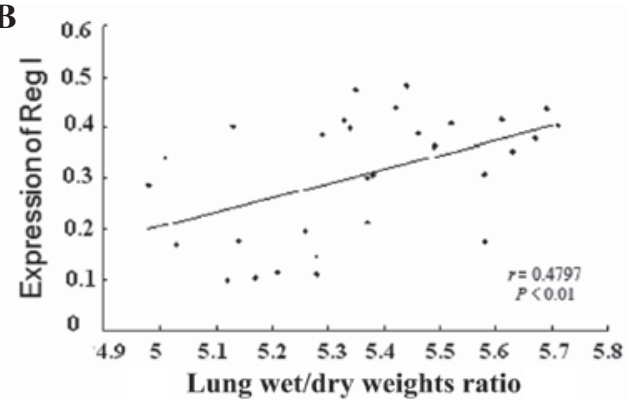

D

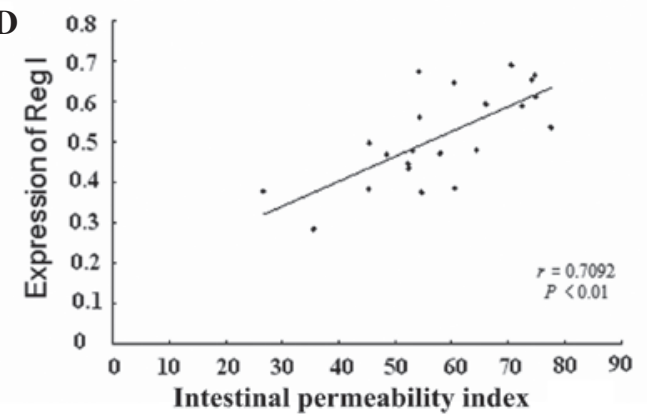

Figure 5. Correlation between the expression of pancreatic regenerating gene (Reg I) in lung tissue and (A) lung histopathologic score and (B) lung wet/dry weight ratio. Correlation between the expression of Reg I in small intestine and (C) mucosal pathological score and (D) the intestinal permeability index.

Table IV. Ratio of rat lung wet/dry weights.

\begin{tabular}{lccc}
\hline Group & $12 \mathrm{~h}$ & $24 \mathrm{~h}$ & $36 \mathrm{~h}$ \\
\hline Control & $4.47 \pm 0.16$ & $4.48 \pm 0.17$ & $4.47 \pm 0.17$ \\
ANP & $5.28 \pm 0.13^{\mathrm{a}}$ & $5.39 \pm 0.21^{\mathrm{a}}$ & $5.47 \pm 0.21^{\mathrm{a}}$ \\
\hline
\end{tabular}

ANP, acute necrotizing pancreatitis. ${ }^{\text {a }}<0.05$, compared with the control group.

Table V. Histological scores of intestinal injury.

\begin{tabular}{lccc}
\hline Group & $12 \mathrm{~h}$ & $24 \mathrm{~h}$ & $36 \mathrm{~h}$ \\
\hline Control & $0.2 \pm 0.42$ & $0.3 \pm 0.48$ & $0.3 \pm 0.48$ \\
ANP & $1.8 \pm 0.89^{\mathrm{a}}$ & $3.3 \pm 1.17^{\mathrm{a}}$ & $4.2 \pm 0.95^{\mathrm{a}}$
\end{tabular}

ANP, acute necrotizing pancreatitis. ${ }^{a} \mathrm{P}<0.01$, compared with the control group.

and are shown in Table IV. The ratios increased significantly in the ANP animals 12, 24 and $36 \mathrm{~h}$ after injection compared with those in the controls $(5.28 \pm 0.13,5.39 \pm 0.21,5.47 \pm 0.21$ vs. $4.47 \pm 0.16,4.48 \pm 0.17,4.47 \pm 0.17$, respectively, $\mathrm{P}<0.05$.

Histological evaluation of intestinal injury. Pancreatitis-induced intestinal injury was mainly manifested by mild hyperemia and edema in the intestinal mucosa proper layer $12 \mathrm{~h}$ after surgery (Fig. 3B) and accelerated edema as well as focal necrosis were observed $24 \mathrm{~h}$ after surgery (Fig. 3C). Massive inflammatory cell infiltration and exfoliation of the mucosal epidermis microvilli were found $36 \mathrm{~h}$ after surgery
Table VI. ${ }^{99 \mathrm{~m}}$ Tc-DTPA excretion rate (\%).

\begin{tabular}{lccc}
\hline Group & $12 \mathrm{~h}$ & $24 \mathrm{~h}$ & $36 \mathrm{~h}$ \\
\hline Control & $4.62 \pm 1.17$ & $6.14 \pm 1.42$ & $7.48 \pm 0.92$ \\
ANP & $34.70 \pm 4.03^{\mathrm{a}}$ & $54.63 \pm 6.94^{\mathrm{a}}$ & $66.83 \pm 7.56^{\mathrm{a}}$
\end{tabular}

99mTc-DTPA, Technetium-99m diethylenetriaminepentacetic acid; ANP, acute necrotizing pancreatitis. ${ }^{a} \mathrm{P}<0.01$, compared with the control group.

(Fig. 3D) compared with the controls (Fig. 3A). The histological scores for intestinal injury were calculated according to previously described criteria (12). As demonstrated in Table V, the histological scores for pancreatitis-associated intestinal injury 12,24 and $36 \mathrm{~h}$ after the induction of ANP were significantly higher than those in the controls $(1.8 \pm 0.89,3.3 \pm 1.17,4.2 \pm 0.95$ vs. $0.2 \pm 0.42,0.3 \pm 0.48,0.3 \pm 0.48$, respectively, $\mathrm{P}<0.01)$. The intestinal permeability was assessed by measuring the 12-, 24- and 36-h urinary excretion rates of ingested ${ }^{99 \mathrm{~m}} \mathrm{Tc}-\mathrm{DTPA}$. As demonstrated in Table VI, the urinary excretion rate of ${ }^{99 \mathrm{~m}}$ Tc-DTPA was significantly elevated at each time-point following the induction of ANP as compared with the controls $(34.70 \pm 4.03,54.63 \pm 6.94,66.83 \pm 7.56$ vs. $4.62 \pm 1.17,6.14 \pm 1.42$, $7.48 \pm 0.92$, respectively, $\mathrm{P}<0.01$ ). The excretion rate of ${ }^{99 \mathrm{~m}} \mathrm{Tc}-$ DTPA tended to increase as the time post-surgery increased, indicating increased intestinal permeability.

Overproduction of Reg I in lung and intestine. To determine whether Reg I mRNA is expressed in rat lung and intestinal tissue, the total RNA was extracted and RT-PCR was performed as described in Materials and methods. As shown in Fig. 4, a PCR product of the expected size (316 bp) was amplified with specific Reg I primers as well as the endogenous control GAPDH 
with an expected size of $671 \mathrm{bp}$. There was a trend towards an increased expression of Reg I mRNA in the lung or intestinal tissue as compared with the controls, indicating that the overproduction of Reg I mRNA correlated with the severity of the disease, while the expression of endogenous control GAPDH was basically unchanged. All RT-PCR trials were performed in triplicate and the intensity ratio of amplicon/GAPDH was analyzed in a semi-quantitative manner.

Correlation analysis. To determine whether the expression levels of Reg I mRNA were correlated with the severity of the pancreatitis-induced pulmonary and intestinal injury, correlation analysis was performed between the Reg I mRNA expression levels and histological scores, ratios of lung wet/dry weights and intestinal permeability indices, respectively. A strong positive correlation between the expression levels of Reg I mRNA in the lung tissue and the histological scores of pulmonary injury was found, with a correlation coefficient of 0.5212 (Fig. 5A, $r=0.5212$, $\mathrm{P}<0.01$ ), implying that the upregulation of Reg I mRNA in lung tissue is correlated with the severity of the pancreatitis-induced pulmonary injury. Similarly, a positive correlation between the expression levels of Reg I mRNA and the ratio of lung wet/dry weights was also observed (Fig. 5B, $r=0.4797$, $P<0.01$ ). In addition, we also identified a positive correlation between the Reg I mRNA expression levels in intestinal tissue and the histological scores of intestinal injury (Fig. 5C, r=0.6728, $\mathrm{P}<0.01$ ) as well as with the intestinal permeability index (Fig. 5D, $r=0.7092$, $\mathrm{P}<0.01$ ), implying that the overproduction of Reg I mRNA in intestinal tissue is correlated with the severity of the pancreatitis-induced intestinal injury.

\section{Discussion}

Since the discovery of Reg I, considerable attention has focused on elucidating its role in the pathogenesis of diseases. Reg I, originally identified as a regenerative growth factor for rat pancreatic islet cells, has been reported to be expressed in various organs, including the pancreas, stomach, kidney and small intestine. It has been shown that Reg I fulfils a role in cell growth that is required for the regeneration and maintenance of tissues in these organs. Reg elevation has been reported in conditions of inflammation and infection, and in response to surgical stimuli (15). In the present study, we found that the upregulation of Reg I mRNA in lung tissue has a positive correlation with the severity of the ALI induced by ANP, which is in accordance with a study in which PSP/reg was suggested to be a biomarker related to organ failure and outcome in ventilator-associated pneumonia (16). Although the mechanism of action of Reg I in lung tissue is unknown, it is presumed that Reg I functions as a pro-regenerating mediator in impaired tissue in response to stress signals, possibly through the induction of the MAPK p38 pathway due to the expression of Reg I receptors in impaired lung tissue, based on similar findings in pancreatic disease $(8,17)$. The upregulation of Reg I in impaired lung tissue may also be a consequence of stimulation by inflammatory cytokines, including INF- $\gamma$ and IL-6, as reported by Sekikawa et al in early gastric cancer, and its protein product may protect AGS cells from apoptosis (18). To the best of our knowledge, our study is the first to show the expression of Reg I in lung tissue. We also provide evidence of the correlation of Reg I mRNA expression levels in lung and the severity of the disease, which indicates that Reg I is a potent biomarker for the severity of pancreatitis-associated ALI. However, the expression of Reg I in impaired lung tissue and its trophic role require confirmation by further study.

Gastrointestinal injury induced by pancreatitis also contributes to the progress of disease and mortality. Deficiency in the intestinal mucosal barrier may lead to an increase of intestinal permeability followed by translocation of bacteria, endotoxemia and secondary infection of the pancreatic tissue, and then cause systemic inflammatory reponse syndrome (SIRS) or MODS. In the present study, a strong positive correlation was found between the expression of Reg I in intestinal tissue and histological scores of intestinal injury $(r=0.6728$, $\mathrm{P}<0.01)$. Since intestinal permeability strongly correlates with endotoxemia, organ failure and mortality in patients with acute pancreatitis (3), the correlation between Reg I expression and intestinal permeability was tested in our study. A positive correlation was identified $(\mathrm{r}=0.7092, \mathrm{P}<0.01)$. A recent study revealed a protective role of Reg I against NSAID-induced small intestinal injuries in a Reg I-knockout mouse model and additional recombinant Reg I effectively attenuated such injuries (19). The results of a further study support the role of Reg in the healing of gastrointestinal mucosal lesions (20). Furthermore, Reg I may also be effective against other small intestinal injuries, including inflammatory bowel disease, since it has been demonstrated that Reg I is upregulated and promotes cell proliferation under other stress conditions (21). Consistent with these studies, we demonstrated the upregulation of Reg I in injured intestinal tissue and a strong positive correlation with the severity of the disease. We postulate that Reg I protected against the intestinal injury induced by ANP in our rat model.

In summary, we conclude that Reg I may be a potent biomarker for the severity of pulmonary and intestinal injuries induced by severe pancreatitis and pancreatitis per se while its exact mechanism in the pathogenesis of these diseases requires further investigation.

\section{References}

1. Hartwig W, Werner J, Müller CA, Uhl W and Büchler MW: Surgical management of severe pancreatitis including sterile necrosis. J Hepatobiliary Pancreat Surg 9: 429-435, 2002.

2. Appelros S and Borgström A: Incidence, aetiology and mortality rate of acute pancreatitis over 10 years in a defined urban population in Sweden. Br J Surg 86: 465-470, 1999.

3. Ammori BJ, Leeder PC, King RF, Barclay GR, Martin IG, Larvin M and McMahon MJ: Early increase in intestinal permeability in patients with severe acute pancreatitis: correlation with endotoxemia, organ failure, and mortality. J Gastrointest Surg 3: 252-262, 1999.

4. Okamoto H: The Reg gene family and Reg proteins: with special attention to the regeneration of pancreatic beta-cells. J Hepatobiliary Pancreat Surg 6: 254-262, 1999.

5. Zhang YW, Ding LS and Lai MD: Reg gene family and human diseases. World J Gastroenterol 9: 2635-2641, 2003.

6. Zheng HC, Sugawara A, Okamoto H, Takasawa S, Takahashi H, Masuda S and Takano Y: Expression profile of the REG gene family in colorectal carcinoma. J Histochem Cytochem 59: 106-115, 2011.

7. Planas R, Pujol-Autonell I, Ruiz E, Montraveta M, Cabre E, Lucas-Martin A, Pujol-Borrell R, Martinez-Caceres E and Vives-Pi M: Regenerating gene I $\alpha$ is a biomarker for diagnosis and monitoring of celiac disease: a preliminary study. Transl Res 158: 140-145, 2011. 
8. Bluth MH, Patel SA, Dieckgraefe BK, Okamoto $\mathrm{H}$ and Zenilman ME: Pancreatic regenerating protein (reg I) and reg I receptor mRNA are upregulated in rat pancreas after induction of acute pancreatitis. World J Gastroenterol 12: 4511-4516, 2006.

9. Lin YY, Viterbo D, Mueller CM, Stanek AE, Smith-Norowitz T, Drew H, Wadgaonkar R, Zenilman ME and Bluth $\mathrm{MH}$ : Small-interference RNA gene knockdown of pancreatitis-associated proteins in rat acute pancreatitis. Pancreas 36: 402-410, 2008.

10. Viterbo D, Callender GE, DiMaio T, Mueller CM, SmithNorowitz T, Zenilman ME and Bluth MH: Administration of anti-Reg I and anti-PAPII antibodies worsens pancreatitis. JOP 10: 15-23, 2009.

11. Yekebas EF, Strate T, Zolmajd S, et al: Impact of different modalities of continuous venovenous hemofiltration on sepsisinduced alterations in experimental pancreatitis. Kidney Int 62 : 1806-1818, 2002.

12. Park PO, Haglund U, Bulkley GB and Fält K: The sequence of development of intestinal tissue injury after strangulation ischemia and reperfusion. Surgery 107: 574-580, 1990.

13. Sun SL, Wu SD and Zhang XB: Oral (99m)Tc-DTPA simultaneous determination of duodenobiliary reflux and intestinal permeability in patients after choledocholithotomy plus T-tube drainage. Hepatobiliary Pancreat Dis Int 4: 593-596, 2005.

14. Schmidt J, Rattner DW, Lewandrowski K, Compton CC, Mandavilli U, Knoefel WT and Warshaw AL: A better model of acute pancreatitis for evaluating therapy. Ann Surg 215: 44-56, 1992.
15. Bimmler D, Schiesser M, Perren A, Scheele G, Angst E, Meili S, Ammann R and Graf R: Coordinate regulation of PSP/reg and PAP isoforms as a family of secretory stress proteins in an animal model of chronic pancreatitis. J Surg Res 118: 122-135, 2004.

16. Boeck L, Graf R, Eggimann P, et al: Pancreatic stone protein: a marker of organ failure and outcome in ventilator-associated pneumonia. Chest 140: 925-932, 2011.

17. Zenilman ME, Zheng QH,Wu H and Rengabashyam P: Pancreatic Reg and a conserved bioactive fragment are mitogenic through the MAPK P38 pathway. Surg Forum 191 (Suppl 1): S29, 2000.

18. Sekikawa A, Fukui H, Fujii S, et al: REG Ialpha protein may function as a trophic and/or anti-apoptotic factor in the development of gastric cancer. Gastroenterology 128: 642-653, 2005.

19. Imaoka H, Ishihara $\mathrm{S}$, Kazumori $\mathrm{H}$, et al: Exacerbation of indomethacin-induced small intestinal injuries in Reg I-knockout mice. Am J Physiol Gastrointest Liver Physiol 299: G311-G319, 2010.

20. Kawanami C, Fukui H, Kinoshita Y, Nakata H, Asahara M, Matsushima Y, Kishi K and Chiba T: Regenerating gene expression in normal gastric mucosa and indomethacin-induced mucosal lesions of the rat. J Gastroenterol 32: 12-18, 1997.

21. Dieckgraefe BK, Crimmins DL, Landt V, Houchen C, Anant S, Porche-Sorbet R and Ladenson JH: Expression of the regenerating gene family in inflammatory bowel disease mucosa: Reg Ialpha upregulation, processing, and antiapoptotic activity. J Investig Med 50: 421-434, 2002. 